\title{
Effect of High-Stakes Exams on Creative Writing Skills of ESL Learners in Pakistan
}

\author{
* Muhammad Ilyas Mahmood, Director (Corresponding Author) \\ ** Mobashra Mobeen, Visiting Lecturer \\ **** Sajid Abbas
}

\begin{abstract}
Creative writing owns an important place in the education system. It enlightens creativity and boosts critical thinking among students. Therefore, it appears to be a ruling skill. Knowing that conventional high-stakes examination leaves a key impact on teaching and learning, the present study was designed to identify the effect of high-stakes exams on creative writing skills of secondary level students of English as a Second Language (ESL) in Pakistan. For this, the content of a series of seven English tests by $8^{\text {th }}, 9^{\text {th }}$, and $10^{\text {th }}$ graders (separately) taken in one of the two spans of private coaching at a renowned tuition center for preparation of high-stakes exams was analyzed to see incremental change in students' creative writing abilities. Analysis discovered that the whole of students' content was mere replicas of ready-made notes except few traces of original effort by students only in the beginning. It was revealed that the system of examination is producing crammers rather than developing real writing skills among students. The study recommended that the examination should include such writing tasks as should gear the education system to develop original creative writing skills among students.
\end{abstract}

Keywords: Creative Writing, English Language Exams, Creative Tasks

\section{Introduction \& Background}

Learning to write effectively is a fundamental component of education and the ability to do so could be a great asset for students throughout their lives (Berdan, 2006). Proficiency in creative writing is one of the highest aims of teaching writing as it involves almost all basic and advanced skills of writing, including writing mechanics, perceiving, developing, organizing, and drafting an idea in the most appropriate way. Creative writing invokes critical thinking (Fay, 2007) and thus seems ruling all fields of knowledge and life whereas apparently, it looks like a single aspect of language teaching. Consequently, creative writing gains a special place in education as it equips children with basic language skills and provides the opportunity for free expression of what they feel and experience.

In most cases, teaching and learning of creative writing have always proved a very difficult task at all levels and in all situations with a reason that it calls forth multi-skills. Creative writing has always been a challenge even in the native language. But when the case is in the second language, the difficulty is multiplied. Added to it, if the methodology of the system is not appropriate, the matter becomes grievous.

Pakistan is a creative region and has a wide creative heritage as this soil has produced several great literary names in Urdu, Punjabi, and Saraiki languages. But the ratio has gradually reduced in bulk and worth. Today we are up to a point of an apprehension that the upcoming future may not be able to see such creative minds.

Besides this, in general life too, most people are found less creative and hardly critical. The main reason working behind this scenario is flawed education set up whose examination system is largely responsible for marring the creative abilities of the nation's students. Many report examination systems as one of the main factors killing the creative abilities of students (e.g. Siddiqui, 2007, p.161; Warsi, 2004). Moreover, this has also become our national behavior to snub our children when they put up new and different questions which are the queries of their growing mind. Siddiqui (2007) finds that 'if the children ask questions, the teacher as well as parents instead of responding to them

\footnotetext{
* Centre for English Language and Learning, University of Okara, Pakistan Email: ilyas.edu.tesl@gmail.com

** Centre for English Language and Learning, University of Okara, Pakistan

*** Punjab Government School Education Department, Punjab, Pakistan
} 
properly, the elders snub them. Since their early childhood, their habit of questioning and freedom of expression are discouraged at home as well as at schools. Their questions are named as silly, nonsense and unethical; thus, their creative ability is not exposed; their thinking skills are slaughtered mercilessly; ultimately children are neither able to think creatively nor to express their ideas through their writing'. Our examination system seeks to test students' memorization rather than assessing actual understanding of the concept and their creative and critical abilities.

In such a phenomenon, English creative writing is suffering worse than all. Even master level students are found reluctant and rather terrified of the thought of writing by themselves. Secondary School Certificate is an important basic public examination. Creative writing is extensively recognized in Pakistani education through school to graduation, but, notably, 'creative writing has been reduced to a set of formulae taught through a series of exercises' (Myhill, 2001, p. 19). As defined by Humaira (2011), secondary school English in Pakistan includes story writing, essay writing, paragraph writing, letter writing, and dialogue writing as genres of creative writing (p.114).This level has only one end year summative high-stakes exam in the $9^{\text {th }}$ grade and one end year summative high-stakes exam in the $10^{\text {th }}$ grade (sometimes one high-stakes exam for both grades). Therefore, the whole focus of the education is on this three-hour paper taken once in a year. This three hours' paper drives the whole curriculum, thus cannot be appropriately representative. Mostly, it concerns the factual knowledge of students rather than assessing their creative writing abilities, critical thinking, or analytical skills. Moreover, validity and reliability of examination papers with regards to coverage of curriculum, selection of paper setters, lack of training for the paper setters and examiners, marking system, and tabulation of results are also suspected (Bhatti, 1987; Warwick and Reimers, 1995; Greaney and Hasan 1998; Mirza, 1997).

An analysis of the past papers shows that creative writing exams are topic-based (Siddiqui, 2007; Humaira, 2011). Topics are usually repeated in the exams, and hence can be easily predicted. Even at established government, private and semi-government schools it is made compulsory for students to solve the past papers for preparation of final exams.

Punjab Textbook Board has specified an English Grammar \& Composition book for matric students, not revised for the last 13 years, and this book is intensively taught in the classes. Students are made cram the book as contents of the book are given in the exams as they are. The list of topics is officially followed. Moreover, the teachers have reduced the list according to the occurrence of few specific topics in the exams as Siddiqui (2007) finds that "most of the examinations in the mainstream schools and colleges are memory-driven. There are certain sets of questions about the textbooks which are most likely to appear in the examination paper". Rahman (2002) also observes that most students depend on cramming. They do not receive any learning on the nature and types of creative writing. They do not know about the techniques of writing creatively. They seldom write short stories, essays, or poetry'. Worse than using the translation method is that even translation sentences are given in the exams the same as they stay in the book. Therefore, the students prefer to learn the sentences also by heart rather than understanding. Even brilliant students do the same just with a fear that they may not miss marks in the exams. The same is the case with preparing reading comprehension. There are 50 comprehension passages in the book. Students can avail solved answers for the comprehension questions from "Get through guides" (Siddiqui, 2007) or teachers' notes and they cram them as it is. Teachers have no choice suggesting cramming to their students. This situation poses an open challenge to teachers' professional autonomy (Burgess et al, 2002; Fisher, 2004).

This practice has also produced pseudo teachers in every street claiming master coaching for matric English as preparation of exams needs no professional skills. The teacher only must assign topics, take tests, and mark it word by word keeping the ready-made notes before the eyes.

Quite at the beginning of the year, students are handed a list of topics and selected materials to be memorized one by one. If any of the students tries to produce his own, it is definite that he would make a few or more mistakes, the teacher suggests him not to write his own but cram from a guide or notes. Here the basic principle of 'learning by trial and error' (Thorndike, 1898) is found at challenge. By chance, if there is any student who is quite able to produce his own with the correct language, very soon the teacher advises him or he feels it better to cram from some expert source to gain competitive marks. The best in cramming is the best in scores. No doubt the students succeed in getting good marks, but their creativity is dulled (Siddiqui, 2007). The case suggests that the more are the marks the less is the creativity. In this way, on one hand, the examination system is driving the 
students away from creative ability and on the other hand, it is not providing correct evaluations of students' creative capacities. This factor claims a challenge against the validity of matriculate English tests.

Siddiqui (2007, p. 189) believes 'in Pakistan, the assessment system excludes creativity and critical thinking out of its legitimate boundaries'. Equally the students' performance in the exams is the descriptor of students' achievement, teachers' ability, and the school's prestige. Moreover, teachers' promotion also depends on their students' results in the public exams (annual progress report attached as specimen). Therefore, the whole system revolves around exams, taking no care of whether the real skills are being developed or not. Some schools (especially the private sector) in competition with the other parallel and to win a name in the vicinity, try to trace question papers or pursue their students' answer sheets to bring good percentages or positions in the area or the board. Malpractices and cheating in exams are a common culture (Daily Dawn Karachi, April 1, 2000). Newspapers (Dawn, June 2, 2001) also report that exam papers get leaked out hours before the exam and sold to students, even at degree levels including M.B.B.S. (Dawn 16 August 2001). Best teacher awards are showered on those whose students gain good scores in the exams. Several studies have criticized the public exams in Pakistan (e.g. Bhatti, 1987; Warwick \& Reimers, 1995; Greaney \& Hasan, 1998; Mirza, 1997; Greaney \& Hasan, 1998 have cited several unpublished papers, reports, and research studies mostly done for the Government of the Punjab). The National Education Policy (1992, p. 69) itself states that 'we are caught in a vicious circle; the cycle begins at a badly constructed syllabi and ends at a rag bag system called examination'.

Some private school systems are offering such an education and assessment system which widely concerns to enhance and evaluate students' creative abilities/writing but education there is highly expensive, out of reach for lower, middle, and upper-middle class. Besides, most parents believe as to why to admit their child in these schools when in the long end they must lead their child through national public exams for secondary or higher secondary instead of O levels or A-Levels. Both systems are different with regards to syllabi, conduct of exams, ways of assessment, reliability, and credibility (Naqvi, 2002).

This situation is quite alarming because creative writing is less to do with English as a language but more with a man's overall life as it also boosts learners' personal development. Its practice can sharpen a man to be an insightful scientist, a shrewd engineer, a wise doctor, a perfect researcher, a successful businessman, an inspiring teacher, an accurate planner, and many more.

Owing to its seriousness, not many researches have raised the issue. Moreover, with regards to the effect of exams on a student's creative writing, no study has investigated the incremental change in a students' draft while being exposed to an exam preparatory system up to a complete cycle of training.

The present study was, thus, framed to analyze a series of students' English tests to see how an exam based training boosts students' ability to get good marks and how it affects their creative ability linked to the degree of their exposure to the system.

\section{Statement of the Problem}

This study was rooted in the assumption that secondary level high-stakes exam in Pakistan is affecting students creative writing abilities. It is assumed that the system is leading the students towards cramming ready-made materials rather than developing their creative writing capacities.

\section{Objectives of the Study}

The study aimed:

To analyze the incremental change in the students' creative writing skills on exposure to specific training for high stakes exams.

\section{Research Questions}

The study investigated the following research questions:

1. What is the incremental change in the students' story writing skills on exposure to specific training for high-stakes exams?

2. What is the incremental change in the students' essay writing skills on exposure to specific training for high-stakes exams?

3. What is the incremental change in the students' paragraph writing skill on exposure to specific training for high-stakes exams? 
4. What is the incremental change in the students' letter writing skills on exposure to specific training for high-stakes exams?

5. What is the incremental change in the students' dialogue writing skill on exposure to private tuition for specific training?

Operationally, the study recognizes story writing, essay writing, paragraph writing, letter writing, and dialogue writing as genres of creative writing (see Humaira, 2011, p.114). And by highstakes exams, the study means tests which carry 'serious consequences for students and educators' (see Marchant, 2004, p.2).

The incremental change was determined by focusing on:

- How much part of the students' drafts occupied the use of their language and idea and how much of them was done merely by rote.

- What is the ratio of grammatical and spelling mistakes in both attempts of them either self-

\section{Sample}

created or done by rote?

$879^{\text {th }}$ and $10^{\text {th }}$ grader were the participants of the study taken from a high score performing set up chosen purposively. This set up is very well known for producing students with high percentages of scores. They have two spans of series for preparing $9^{\text {th }}$ and $10^{\text {th }}$ grader students for high-stakes exams. Students' incremental tests of English in the first span of their preparation were availed despite great reluctance at the part of the administration. English was a second language for all students. The sample contained both genders.

\section{Development of Instruments}

As the present study aimed to investigate the effect of high-stakes exams on creative writing skill of secondary school learners of English as a second language, all drafts of students' tests within one of the two spans of their training for high-stakes exams were taken as the data source and their creative writing content was analyzed with the help of a self-developed rubric (Appendix I) which deals with the data into series test number, genre of creative writing, number of Self-Created/ By Rote words and number of mistakes in each part. In this way, the study could be able to note the incremental change in the students' drafts with regards to their creation or based on cramming from prescribed notes $o$ guides.

Table 1

Data Rubric

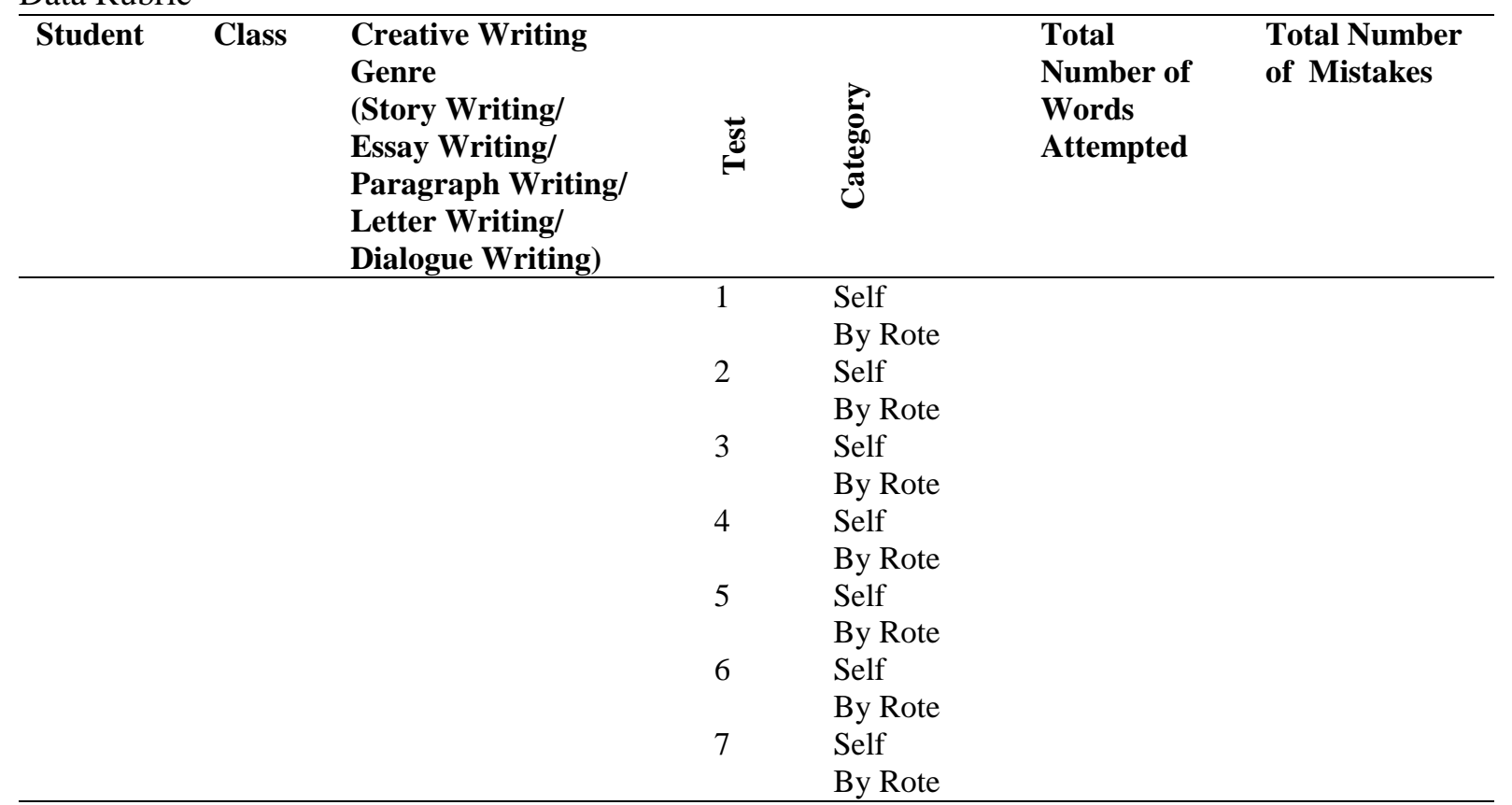

Validation of Instruments

The rubric was very carefully made and validated by consultation with experts and piloting before applying for original data. 


\section{Data Analysis Methods}

The researcher had to be very careful in identifying the parts which were students' creations or those done merely by rote. After the rubrics were filled, simple percentages were drawn from the respective words attempted and mistakes made using Microsoft Excel.

\section{Results}

This part presents the data interpretation with the help of tables and graphs.

Table 2

Percentages of Words Attempted by Self-Creation or By Rote (in Story, Essay, Paragraph, Letter, and Dialogue)

\begin{tabular}{ccccccccccc}
\hline \multirow{2}{*}{ Tests } & \multicolumn{2}{c}{ Story } & \multicolumn{2}{c}{ Essay } & \multicolumn{2}{c}{ Paragraph } & \multicolumn{2}{c}{ Letter } & \multicolumn{2}{c}{ Dialogue } \\
\cline { 2 - 10 } & $\begin{array}{c}\text { Self- } \\
\text { Creation }\end{array}$ & Bote & $\begin{array}{c}\text { Self- } \\
\text { Creation }\end{array}$ & $\begin{array}{c}\text { By } \\
\text { Rote }\end{array}$ & $\begin{array}{c}\text { Self- } \\
\text { Creation }\end{array}$ & $\begin{array}{c}\text { By } \\
\text { Rote }\end{array}$ & $\begin{array}{c}\text { Self- } \\
\text { Creation }\end{array}$ & $\begin{array}{c}\text { By } \\
\text { Rote }\end{array}$ & $\begin{array}{c}\text { Self- } \\
\text { Creation }\end{array}$ & $\begin{array}{c}\text { By } \\
\text { Rote }\end{array}$ \\
\hline 1 & - & - & $64 \%$ & $36 \%$ & - & - & $58 \%$ & $42 \%$ & - & - \\
2 & - & - & $49 \%$ & $51 \%$ & - & - & $52 \%$ & $48 \%$ & - & - \\
3 & - & - & $43 \%$ & $57 \%$ & - & - & $41 \%$ & $59 \%$ & - & - \\
4 & - & - & $38 \%$ & $62 \%$ & - & - & $34 \%$ & $66 \%$ & - & - \\
5 & - & - & $34 \%$ & $66 \%$ & - & - & $23 \%$ & $77 \%$ & - & - \\
6 & - & - & $28 \%$ & $72 \%$ & - & - & $16 \%$ & $84 \%$ & - & - \\
7 & - & - & $16 \%$ & $84 \%$ & - & - & $9 \%$ & $91 \%$ & - & - \\
\hline
\end{tabular}

Test 1-Data from Story, Essay, Paragraph, Letter and Dialogue in the English test for Class IX and Class X,

Test 2-Data from Story, Essay, Paragraph, Letter and Dialogue in the English test for Class IX and Class X,

Test 3-Data from Story, Essay, Paragraph, Letter and Dialogue in the English test for Class IX and Class X,

Test 4-Data from Story, Essay, Paragraph, Letter and Dialogue in the English test for Class IX and Class X,

Test 5-Data from Story, Essay, Paragraph, Letter and Dialogue in the English test for Class IX and Class X,

Test 6-Data from Story, Essay, Paragraph, Letter and Dialogue in the English test for Class IX and Class X,

Test 7-Data from Story, Essay, Paragraph, Letter, and Dialogue in the English test for Class IX and Class X.

As shown in the table, none of the students' had attempted a story, paragraph, or dialogue. The data shows that rote material is occupying more and more place in students' drafts as soon as they start preparing for their high-stakes exam. Their creation can be noted decreasing and dying with every day passing. In the same way, it is also notable that none of the students attempted the story, paragraph, and dialogue.

Table 3

Percentages of Mistakes Committed in Students' Self-Created or By Rote Content in the Essay

\begin{tabular}{ccccc}
\hline Tests & \multicolumn{2}{c}{ Self-Creation } & Bords & By Rote \\
\cline { 2 - 5 } & Words & Mistakes & $36 \%$ & $18 \%$ \\
\hline 1 & $64 \%$ & $41 \%$ & $51 \%$ & $21 \%$ \\
2 & $49 \%$ & $43 \%$ & $57 \%$ & $22 \%$ \\
3 & $43 \%$ & $39 \%$ & $62 \%$ & $20 \%$ \\
4 & $38 \%$ & $42 \%$ & $66 \%$ & $17 \%$ \\
5 & $34 \%$ & $44 \%$ & $72 \%$ & $13 \%$ \\
6 & $28 \%$ & $39 \%$ & $84 \%$ & $9 \%$ \\
7 & $16 \%$ & &
\end{tabular}

Test 1-Data from Story, Essay, Paragraph, Letter and Dialogue in the English test for Class IX and Class X,

Test 2-Data from Story, Essay, Paragraph, Letter and Dialogue in the English test for Class IX and Class X,

Test 3-Data from Story, Essay, Paragraph, Letter and Dialogue in the English test for Class IX and Class X,

Test 4-Data from Story, Essay, Paragraph, Letter and Dialogue in the English test for Class IX and 
Class X,

Test 5-Data from Story, Essay, Paragraph, Letter and Dialogue in the English test for Class IX and Class X,

Test 6-Data from Story, Essay, Paragraph, Letter and Dialogue in the English test for Class IX and Class X,

Test 7-Data from Story, Essay, Paragraph, Letter, and Dialogue in the English test for Class IX and Class X.

The table above shows that the ratio of mistakes in students' self-created content remains almost the same with no significant difference from the beginning to the end. On the other hand, in students' By Rote content, the ratio of mistakes increases with an increase in the number of words in the first three tests but after that, the ratio of mistakes starts decreasing significantly even though we note a significant increase in the number of words in the same attempts.

Table 4

Percentages of Mistakes Committed in Students' Self-Created or By Rote Content in the Letter

\begin{tabular}{ccccc}
\hline Tests & \multicolumn{2}{c}{ Self-Creation } & \multicolumn{2}{c}{ By Rote } \\
\cline { 2 - 5 } & Words & Mistakes & Words & Mistakes \\
\hline 1 & $58 \%$ & $46 \%$ & $42 \%$ & $21 \%$ \\
2 & $52 \%$ & $47 \%$ & $48 \%$ & $2 \%$ \\
3 & $41 \%$ & $44 \%$ & $59 \%$ & $23 \%$ \\
4 & $34 \%$ & $43 \%$ & $66 \%$ & $19 \%$ \\
5 & $23 \%$ & $49 \%$ & $77 \%$ & $16 \%$ \\
6 & $16 \%$ & $45 \%$ & $84 \%$ & $14 \%$ \\
7 & $9 \%$ & $43 \%$ & $91 \%$ & $11 \%$ \\
\hline
\end{tabular}

Test 1-Data from Story, Essay, Paragraph, Letter and Dialogue in the English test for Class IX and Class X,

Test 2-Data from Story, Essay, Paragraph, Letter and Dialogue in the English test for Class IX and Class X,

Test 3-Data from Story, Essay, Paragraph, Letter and Dialogue in the English test for Class IX and Class X,

Test 4-Data from Story, Essay, Paragraph, Letter and Dialogue in the English test for Class IX and Class X,

Test 5-Data from Story, Essay, Paragraph, Letter and Dialogue in the English test for Class IX and Class X,

Test 6-Data from Story, Essay, Paragraph, Letter and Dialogue in the English test for Class IX and Class X,

Test 7-Data from Story, Essay, Paragraph, Letter, and Dialogue in the English test for Class IX and Class X.

As from students' letter writing, the table above presents a decrease in students' mistakes in their self-created part but again the decrease is just for $3 \%$ from start to end of the span and still $43 \%$ of students' draft is not correct.

Whereas, in the By Rote part of students, the number of mistakes can be noted increasing with an increase in the number of words in the first three attempts. But in the later tests, there is a significant decrease in the number of mistakes though there is an increase in the number of words attempted by students in the same tests.

\section{Discussion}

The results of the study proposed the following considerations for discussion:

The High-Stakes Exam Producing only Crammers (Rote Learners)

The most alarming finding of the study is that right after their exposure to preparation for high-stakes exams, students' drafts started occupying more and more material that is merely memorization from guidebooks or available notes.

While analyzing students' tests, another thing was noted that only in the first two tests, there were few traces of students' original attempt where the thought and the construction of sentences were students' effort though with mistakes. But in the subsequent tests, no original attempt could be traced. While, in the subsequent tests, the parts which we call students self-attempts, mostly both the idea and the main structure of the sentence from ready-made notes but there were at least two new words, a 
different phrase or a clause added by the student himself. Here, it looks as if the student forgot that part and tried himself to rejoin the continuing draft. This is like the reproduction of the reproduction.

Here, it may be the case that the student tried to write by himself at the beginning of his days at the tuition center but he felt or the teacher suggested him to concentrate more on memorizing answers than trying to produce them by self to avoid mistakes to get through the exam.

This practice is quite alarming and a threat to real learning raising a challenge to the theory of trial and error (see Thorndike, 1898 for supportive details). In this way, the doors for learning to write by self are closed right at the beginning of training for the high-stakes exam and the potential of the child to learn to write creatively is abruptly murdered.

Another thing was also noted that the mistakes were corrected by the teachers quite according to the sources from where they were memorized. If any word or sentence was missing, a hundred percent the same word and the sentence was suggested by the teacher as they occurred in the notes or the concerned book.

During analysis, a paper came to view where one of the students had tried to write the whole of the essay by himself. This was pleasing to see that the student had used his idea and tried to construct the sentences by himself even though with mistakes. But instead of encouraging and providing the student with remedial guidelines, the teacher had given him a note that he needed to work hard and further suggested he learn the essay by heart from some source. The researcher was interested to see the same student's next attempt in the next test. It was desperate to find that this time the same student had written only memorized content from the notes. This time, he had not attempted on his own, except a little.

The study's data reflects a gradual increase in the students' memorized part in such a way that it appears as if no student will be daring to include his effort by the time they are ready for the final high-stakes exams 'under the threat of losing marks' (see Humira, 2011 for support). This is happening only under the effect of memory-driven questions in the exams. This finding of the study also avails support from Rahman (2002); Siddiqui (2007); Arifa (2009); Mansoor (2009); Humaira (2011) and Haider (2012).

\section{Selective Preparation}

The analysis of the students' papers revealed that none of the students attempted a story, letter, or dialogue in all the assessments held during the complete span.

The simple reason is that the high-stakes exam paper offers a choice to students as they can attempt any one out of two or more genres. They are free to choose a) letter or story or dialogue; b) essay or paragraph. Students choose those genres which are comparatively easy to attempt and can bring them marks. In this support, Shah and Afzaal (2004) and Christie and Afzaal (2005) also believe that this 'selective study approach' helps students not only pass the exam but also score good marks. In this situation, Grant, Gradwell \& Cimbricz(2004) and Smith, Edelsky, Draper, Rottenberg \& Cherland (1990) report teachers neglecting the topics which carry no place in the exam.

The finding suggests that it is not what they decide right at the time in the examination hall, but they take this decision quite while they are preparing for the final exams. During data collection for this study, related question papers were also collected from the teaching center. The researcher was surprised by the overview of the question papers that they did not include any question about story, paragraph, or dialogue. It shows that it was already decided by the center to skip these genres for preparation of the final exams as letters and essays were a better choice for them to get through the exam. This is not only with this study's group, but in most cases, students prefer to select essays rather than paragraphs, letters from story or dialogue, and summary from paraphrasing. Whereas, writing story, dialogue, paragraph writing, or paraphrasing are more interesting and easier. Students can write freely on these genres without much effort and they need no hard and fast mechanics to follow. Moreover, they are more life-like. Teachers and students also avoid options that require them to write on their own as a paraphrasing of poetic lines etc. On the other hand, a very poor thing to describe is that it is advised to the paper examiners that the student should be given marks even if the student provides only the heading, greeting, closing, and signature without writing anything for the body of the letter.

Marks are specified separately for each part. This study also found some students who attempted only the above-mentioned parts of the letter partially or wholly correct. They wrote nothing for the body of the letter or even some of them only did a filling up of the space not relevant or 
correct. Most of the students started the body of the letter with traditional words like "I hope this letter of mine will find you in the best of conditions. I am extremely sorry for not replying to your letter in time. I have been suffering from malaria for the last two weeks" (students' same words have been quoted here). Some cases wrote other parts of the letter and only these lines for the body. And the teacher had added them one mark for these lines along-with 3 marks for address and salutation, and 1 for closing. And he had done that following the high-stakes exam's marking criteria. One more thing was discovered that most of the students had used the same name for their friend in the letter as it was used in the notes or the book. Only a few students had used a different name.

This scheme of selection raises a challenge regarding the logical integration of contents and activities across curriculum grades. Here, students are dropping stories, dialogue, paragraphs, and paraphrasing. At the intermediate level, students have a choice between letter or application and here to most students prefer to drop application. In the same way, in their Bachelor's degree, they too have a choice between letter and application, and here too the students do not prepare applications when they have an option to opt for writing a letter to the editor about some social problem. In this way, application writing is missed in all curriculum grades, whereas it has a wide importance and need, especially for educated people.

In this scenario, we also come across some newly inducted teachers who are very ambitious and enthusiastic to train the students on actual grounds so to develop original skills of writing. But soon they are advised by their coordinators or seniors to follow the lines to prepare the students for a list of topics as they occur as it is in the high-stakes exams. They, very soon, feel that they do not have enough time to prepare the students to be good writers and be able to get through the exams with good scores at the same. They think it only wise to focus on driving the students to cram for the list of topics in "New Grammar and Composition by PTB. The book presents 16 letters, 17 essays, 12 stories, and 50 comprehension passages. The high-stakes paper is always set according to these topics and these topics are repeatedly occurring in the final exams as Shah and Afzaal (2004) and Christie and Afzaal (2005) also report a recurrence of questions in the exams. Sometimes, the same topics are repeated in continuous years (Humaira, 2011). And teachers always follow this list, or even this list is reduced for medium and weaker students.

More, translation of sentences or parts from Urdu to English, and comprehension passages are also given from the same book.

\section{No Teacher-Student Autonomy}

The teachers and students are forced by the assessment system as they have no choice other than adopting learning answers of the oft-repeated questions by rote which is collectively considered the best means of getting good scores. Notably, the compulsion of a prescriptive curriculum and closely defined system of assessment has laid a challenge on the professional autonomy of teachers and hampered their creativity (Burgess et al, 2002; Fisher, 2004). Here, the system is damaging the autonomy of both the front-line agents i.e. students and teachers. Counting several harmful effects of high-stakes testing, Smith (1991) reports that high-stakes testing potentially reduces "the freedom of teachers to teach content or to use methods that are believed to be incompatible with the format of standardized tests" (p.7) (also receives support from Lam, 1994; Cheng, 1997). Whereas, the advanced world of second language teaching is strenuously focusing on autonomy, especially of the learner. The students find no other way than cramming when they understand that they can only get good grades in the exams. While the teachers' promotion and the school's repute are also wholly dependent on students' marks in their high-stakes exams. Thereupon, how are they going to deviate from the setup? In actuality, the teachers of creative writing are autonomous and competent working towards a vision of learners who can act and think for themselves (Moss, 2001).

\section{Materials Selection}

The fixing of topics by the system and recurrence of questions in the exams has led to get-through guide-books pollution in this context. During the analysis, it was noted that students' drafts were mainly made of materials from three sources which were a) having complex sentences and variety of vocabulary, winning good marks from the teacher; b) having a medium standard of sentences and comparatively lesser variety of vocabulary, taking average marks from the teacher; c) simple and easy, scoring marginal passing marks or failing.

Talking about these guides, Siddiqui (2007) believes that they are a short-cut to pass the examination. In some or the other way, many find that ready-made substandard materials are common 
in this regard (Arifa, 2009; Mansoor, 2009). In the international scenario, Pierce (1992) finds the publishing of exam preparatory books; Hilke and Wadden (1996) see the publishing industry ' a quasieducational business.... which churns out scores of preparatory guides, seminars, and sample tests in countries around the globe'; Lam (1994) find teachers 'text-book slaves'.

\section{No Valid Assessments}

The scenario promotes an understanding that it is not fair to claim high-stakes marks in English to be a true representative of secondary school students' creative writing abilities in this context. Particularly for the attention of the stakeholders, it marks a big challenge on the validity of these assessments. This apprehension also receives support from Fredericksen (1984) who claims that in such situations where score-boosting activities are gearing the whole system, the test results are misinformed about the outcomes of the targeted skill. According to him, the rise in the scores may bring apparent status to school, but this may only be because of following the test demands. In the same way, Linn, Grave, and Sanders (1989); and Shepard (1990) also do not find relevance between students' scores and their ability.

Smith (1991) also believes that 'interpretability of test scores to represent the ability in the domain is threatened' under such conditions.

Such score-raising activities, failing to develop real skills and the abilities, have been dubbed as 'test-score pollution' (Haladyna et al, 1991), 'questionable' (Mehrens and Kaminsky, 1989), 'immoral' (Cannell, 1987), or 'unethical' (Haladyna et al, 1991). Following these reverse names Davies (1990) suggests that it is more rational to make the high-stakes tests beneficial than to abolish them. Messick (1996) finds that only valid tests are more likely to leave a positive influence on teaching and learning.

\section{Limitations of the Study}

The findings of the study could have availed more strength if it could also include the analysis of the relationship between students' ability to cram and their scores in their previous high-stakes exams. For this, the relationship of the ranking of students' ability to cram in their last test at the private tuition center could be seen against the ranking of their marks in their previous high-stakes English exams in the same group.

\section{Conclusions}

Below are the conclusions of the study:

No student attempts paraphrasing of the poetic lines, dialogue writing, paragraph writing, and story writing as they have essay writing, letter writing, and summary of the poem writing as a choice against them.

The Secondary School high-stakes examinations (Board Exam) are negatively affecting the creative writing of matric students. It is training students to be the best in cramming. The students start leaving writing by themselves as soon as they are under the effect of their high-stakes exams.

Despite controlled training, students are making the same range and type of mistakes from the beginning to the end. The training for the secondary school high-stakes exams produces no improvement in students' creative writing skills. In this regard, they pass and move to the next grade with the same poorness of skill as they entered the last grade.

The high-stakes exams for matric level English has put a shut-up tape on teacher and student's autonomy as both have no choice than choosing to cram of traditional topics.

There is no original attempt to be noticed in the students' papers except a little in their very beginning days at the tuition center. All is a copy of the academy's notes, English Grammar \& Composition by PTB (Punjab Textbook Board), or other guidebooks suggested by their teachers.

The best in cramming is the best in getting scores.

High-stakes assessments for secondary school English are not true representative of students' creative writing abilities; thus, they are not valid.

\section{Recommendations}

The discussion of the findings of the study proposes the following recommendations:

Tests must satisfy the criteria of validity.

There should be no repetition of questions in the exams.

The high-stakes exams should include unseen tasks instead.

Students should receive positive feedback for making their writings. 
Students' self-attempts in writing should be properly checked by teachers and the teachers should provide them proper corrections, and remedies for their mistakes.

Formative assessments should also be part of students' decision-making evaluations (The Ministry of Education, 2009) has already recommended periodic assessments). regard.

Available literature on producing a positive effect of exams can be highly helpful in this

There is a need for analysis of teaching-learning resources at hand and understanding of existing situations to develop a practicable framework in this respect.

\section{References}

Arifa, R. (2009). College teachers' perceptions of ELT: Relevance to teacher training, in Mansoor, S, Sikandar, A, Hussain, N, \& Ahsan N. M. (eds.) Emerging Issues in TEFL Challenges for Asia. Oxford: Oxford University Press.

Berdan, K. (2006). Writing for a change: Boasting literacy and learning through social action. National Writing Project. San Francisco: Jossey Bass Teacher.

Bhatti, M. A. (1987). Secondary education in Pakistan: Perspective planning. Islamabad: National Education Council.

Burgess, T., Fox, C. \& Goody, J. (2002). When the Hurly Burly'sdone: What's worth fighting for in English in education. Sheffield: National Association for Teaching of English.

Cannell, J. J. (1987). Nationally normed elementary achievement testing in America's public schools: How all fifty states are above the national average. Daniels, W.V.: Friends for Education.

Cheng, L. (1997). How does wash back influence teaching? Implications for Hong Kong. Language and Education, 11 (1), 38-53.

Christie, T., \& Afzaal, M. (2005).Rote memorization as a sufficient explanation of secondary school examination achievement in Pakistan: An empirical investigation of a widespread assumption. A paper presented at an IAEA international conference entitled Assessment and the future schooling and learning held at Abuja, Nigeria September 4-9, 2005. Retrieved from http://www.aku.edu/akueb/IAEA05.pdf

Daily Dawn, Karachi http://www.dawn.com/2000/04/01/local23.htm

Daily Dawn, Karachi http://www.dawn.com/2001/06/02/local29.htm

Daily Dawn, Karachi http://www.dawn.com/2001/08/16/local5.htm

Davies, A. (1990).Principles of language testing. Cambridge, MA: Basil Blackwell.

Fay, D. (2007). Student storytelling through sequential art. English Language Teaching Forum, 45(3), $2-11$.

Fisher, R. (2004). Embedding the literacy strategy: snapshots of change. Literacy, 38(3), 134-140.

Fredericksen, N. (1984). The real test bias: Influences on testing and teaching. American Psychologist, (39), 193-202.

Grant, S. J., Gradwell, J. M., \& Cimbricz, S. K. (2004). A question of authenticity: The documentbased question as an assessment of students' knowledge of history. Journal of Curriculum and Supervision, 19(4), 309-337.

Greaney V. \& Hasan, P. (1998). Public examinations in Pakistan: A system in need of reform' in Hoodbhoy, P. Education and the State: Fifty years of Pakistan. Karachi: Oxford University Press.

Haider, G. (2012).Teaching of writing in Pakistan: A review of major pedagogical trends and issues in the teaching of writing. Journal of Educational and Social Research, 2(3), 215-225.

Haladyna, T.M., Nolen, S.B. \& Haas, N.S. (1991). Raising standardized achievement test scores and the origins of test score pollution. Educational Research, 20(5), 2-7.

Hilke, R. \& Wadden, P. (1996). The TOEFL and its imitators: Analyzing the TOEFL and evaluating TOEFL-prep texts. PASAA: A Journal of Language Teaching and Learning in Thailand, (26), 53-67.

Humaira, K. (2011). Testing creative writing in Pakistan: tensions and potential in classroom practice. International Journal of Humanities and Social Science, 1 (15) 111-119.

Lam, H. P. (1994). Methodology washback- an insider's view. In D. Nunan, R. Berry, \& V. Berry (Eds.), Bringing about change in language education: Proceedings of the International Language in Education Conference 1994 (83-102). Hong Kong: University of Hong Kong. 
Linn, R. L., Grave, M. E., \& Sanders, N. M. (1989). Comparing state and district test results to national norms: Interpretations of scoring "above the national average" (CSE Technical Report 308). Boulder: University of Colorado, CRESST.

Mansoor, S. (2009). Regional languages of Pakistan: Issues and concerns for language planning in higher education, in Mansoor, S., Sikandar, A., Hussain, N. \&Ahsan, N. M. (eds.) Emerging Issues in TEFL Challenges for Asia. Oxford: Oxford University Press.

Marchant, G. J. (2004). What is at stake with high-stakes testing? A discussion of issues and research [Electronic version]. Ohio Journal of Science, 104(2), 2-7.

Mehrens, W. A. \& Kaminsky, J. (1989). Methods for improving standardized test scores: fruitful, fruitless, or fraudulent? Educational Measurement: Issues and Practice, 8(1), 14-22.

Messick, S. (1996).Validity and wash back in language testing. Language Testing, 13(3), 241-256.

Ministry of Education (2009).National Education Policy 2009. Islamabad: Government of Pakistan.

Mirza, M. (1997).Examination system and teaching and practice of teachers at secondary, Higher Secondary and O'Level. Bulletin of Education and Research, XIX(1), 14-30.

Moss, P. (2001).The Otherness of Reggio. In Abbott, L. \&Nutbrown, C. (Eds.) Experiencing Reggio Emilia, Implications for Pre-school Provision. Buckingham: Open University Press.

Naqvi, R. (2002).Opting for $O$ and A levels. Daily Dawn $27^{\text {th }}$ December 2002. Karachi. http://www.dawn.com/events/lifestyle2002/ls23.htm

Ministry of Education (1992).National Education Policy1992. Islamabad: Government of Pakistan.

Myhill, D. (2001). Crafting and creating. English in Education, 35(3), 13-20.

Pierce, B. N. (1992). Demystifying the TOEFL reading test. TESOL Quarterly, 26(4), 665-691.

Rahman, T. (2002).Language, ideology, and power: Language learning among the Muslims of Pakistan and North India. Oxford: Oxford University Press.

Shah, D. \& Afzaal, M. (2004).The examination board as educational change agent: the influence of question choice on selective study. paper presented at the $30^{\text {th }}$ annual IAEA Conference. Philadelphia, USA.

Shepard, L.A. (1990). Inflated test scores gains: Is the problem old norms or teaching the test? Educational Measurement Issues and Practice, 9, 15-22.

Siddiqui, S. (2007).Rethinking education in Pakistan: Perceptions, practices, and possibilities. Lahore: Paramount Publishing Press.

Smith, M. L., Edelsky, C., Draper, K., Rottenberg, C., \& Cherland, M. (1990).The role of testing in elementary schools. CSE Technical Report 321.CRESST.University of California.

Smith, M.L. (1991). Put to the test: the effects of external testing on teachers. Educational Researcher, 20(5), 8-11.

Thorndike, E. L. (1898). Animal intelligence: An experimental study of the associative processes in animals. Psychological Monographs: General and Applied, 2(4), i-109.

Warsi, J. (2004). Conditions under which English is taught in Pakistan: An Applied Linguistic Perspective. Sarid Journal. Available: https:// www. sarid.net/sarid-journal (May 10, 2009)

Warwick, D. P. \& Reimers, F. (1995).Hope and despair? Learning in Pakistan's primary schools. USA: Greenwood Publishing Group, Inc. 